\title{
Directional Reflectance Factor Distributions for Cover Types of Northern Africa
}

\author{
D. S. KIMES, W. W. NEWCOMB, and C. J. TUCKER \\ Earth Resources Branch, NASA / Goddard Space Flight Center, Greenbelt, Maryland 20771
}

I. S. ZONNEVELD, W. VAN WIJNGAARDEN, and J. DE LEEUW

International Institute for Aerial Survey and Earth Sciences (ITC), 350 Boulevard 1945, P. O. Box 6, 7500 AA Enschede, The Netherlands

G. F. EPEMA

Department of Soil Science and Geology, Agricultural University, Wageningen, The Netherlands

\begin{abstract}
Directional reflectance factors that spanned the entire exitance hemisphere were collected on the ground throughout the morning period for common cover types in Tunisia, Africa. NOAA $7 / 8$ AVHRR bands $1(0.58-0.68 \mu \mathrm{m})$ and 2 $(0.73-1.1 \mu \mathrm{m})$ were used in data collection. The cover types reported were a plowed field, annual grassland, steppe grassland, hard wheat, salt plain, and irrigated wheat. Several of these cover types had geometric structures that are extreme as compared to those reported in the literature. Comparisons were made between the dynamics of the observed reflectance distributions and those reported in the literature. It was found that the dynamics of the measured data could be explained by a combination of soil and vegetation scattering components. The data and analysis further validated physical principles that cause the reflectance distribution dynamics as proposed by field and simulation studies in the literature. Finally, the normalized difference transformation [(Band $2-$ Band 1$) /($ Band $1+$ Band 2$)]$, which is useful in monitoring vegetation cover, generally decreased the variation in signal with changing view angle. However, several exceptions were noted.
\end{abstract}

\section{Introduction}

Directional reflectance measurements of natural targets are important to remote sensing studies in several ways. First, reflectance factor distributions that span the entire exitance hemisphere and knowledge of their dynamics can be used to improve the interpretation of aircraft and satellite data where the scan angle varies widely for different orientations with respect to the sun (Kirchner et al., 1982). For example, the advanced very high resolution radiometer (AVHRR) data from the NOAA satellites offer the potential of monitoring terrestrial targets with a high temporal frequency for large global areas (Tucker et al., 1983a,b). However, these data are acquired by the radiometer scanning out to $56^{\circ}$ from nadir in the plane normal to the satellite's track, and this variation in viewing angle can significantly alter the sensor response. Secondly, remotely sensed directional data from natural targets as opposed to only a nadir view offers additional information for making inferences about the target's geometric structure (Kimes, 1983; 1984). It may be possible to use information about the geometric structure of the target to identify cover types, and detect and monitor changes in leaf orientation that 
reflect vegetation condition and growth development (Kimes, 1984). And finally, directional measurements that cover the entire exitance hemisphere serve as rigorous validation data for radiative transfer models (Kimes and Kirchner, 1982b). These models advance our physical understanding of the directional scattering properties of natural targets.

The directional reflectance distribution of natural targets is a complex function of the geometric structure and density of the vegetation components, geometric structure of the soil, optical properties of the vegetation and soil components, and the solar zenith and azimuth angles (Kimes, 1984). Knowledge of the dynamics of directional reflectance distributions and the physical principles involved is essential for utilizing directional radiometric measurements intelligently. However, only a few directional reflectance distributions covering the entire exitance hemisphere of vegetation and soil scenes have been measured and published, and very little analysis of such data has been performed (Smith and Ranson, 1979).

In this study, directional reflectance factors that spanned the entire exitance hemisphere were collected on the ground for several natural cover types in Tunisia, Africa. NOAA $7 / 8$ AVHRR Bands 1 $(0.58-0.68 \mu \mathrm{m})$ and $2(0.73-1.1 \mu \mathrm{m})$ were used in data collection. These reflectance distributions were taken at various times of the day for each cover type. The knowledge obtained during the land ecological survey of the ITC made it possible to select sites for measurements that were representative for large parts of the study area. The cover types measured were a plowed field, annual grassland, steppe grassland, hard wheat, salt plain, and irrigated wheat. Several of these cover types have geometric structures which are extreme as compared to the vegetation types commonly reported in the literature. The reflectance distributions were analyzed in regards to two areas. Comparisons were made between the dynamics of the observed reflectance distributions and those reported by Kirchner et al. (1982) and Kimes (1983). Furthermore, the data in this paper was used to further validate the physical principles that caused the observed reflectance distribution dynamics as proposed by Kimes $(1983 ; 1984)$ in his field and simulation studies.

\section{Experiment}

Spectral directional radiances were taken in NOAA satellite $7 / 8$ AVHRR Bands $1(0.58-9.68 \mu \mathrm{m})$ and $2(0.73-1.1$ $\mu \mathrm{m})$ using a Mark III three-band radiometer (Tucker et al., 1981) with a $12^{\circ}$ field of view. From $2 \mathrm{~m}$ above the ground for each measurement period, 41 directions were measured located at nadir and at $15^{\circ}$ increments of off-nadir angle (15, $30,45,60$, and $75^{\circ}$ ) and $45^{\circ}$ increments of azimuth angle $(0,45,90,135,180,225$, 270 , and $315^{\circ}$ ). The $0^{\circ}$ azimuth corresponds to the direction of the sensor looking toward the sun. Thus, an azimuth of 0 and $180^{\circ}$ represents forward scattering and backscattering, respectively. The coordinate system used is shown in Fig. 1 .

For each measurement period, three or four complete directional radiance distributions were taken at different sampling points within the middle of a homogeneous surface. This sampling procedure took $<20 \mathrm{~min}$. All measurements were taken under clear sky conditions. One 


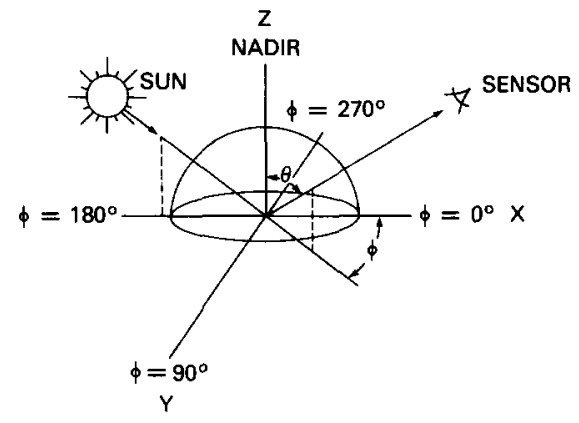

(a)

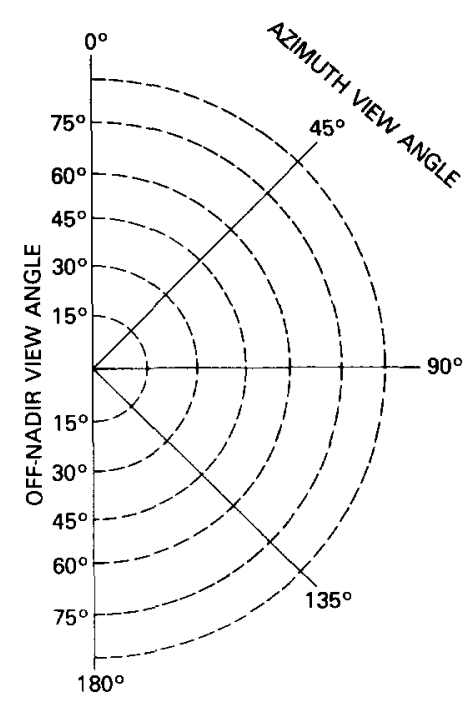

(b)

FIGURE 1. (a) Coordinate system defining solar and sensor angles and (b) polar plot showing scheme for plotting directional reflectance factors. The solar azimuth is always $180^{\circ}$. The sensors azimuth and off-nadir angles are shown as $\phi$ and $\theta$, respectively. A sensor with a $0^{\circ}$ azimuth looks into the sun. Thus, an azimuth of $0^{\circ}$ and $180^{\circ}$ represents forward scattering and backscattering, respectively. The spectral directional reflectance factors were plotted in a polar plot (b), where the distance from the origin represents the off-nadir view angle of the sensor and the angle from $\phi=0^{\circ}$ represents the sensor's azimuth. The cross points show the directional measurements plotted. Only $0-180^{\circ}$ azimuth is shown because azimuthal symmetry about the principle plane of the sun is assumed. The principle plane is defined as the plane perpendicular to the horizontal ground and contains the solar azimuth. Lines of equal reflectance were contoured as presented in Fig. 3. mean distribution was calculated for each measurement period. All mean directional radiance values were divided by the corrected radiance from a barium sulfate panel. The resulting values are reflectance factors. The corrected radiance from the panel refers to corrections made for the non-Lambertian behavior of a reference panel for the specific irradiance conditions as described by Kimes and Kirchner (1982a).

The method of plotting the directional reflectance factor distributions is described in Fig. 1. All of the reflectance data in this study were essentially symmetric about the principle plane of the sun. Therefore, corresponding data points on either side of the principle plane (Fig. 1) were averaged (e.g., azimuths 45 and $315^{\circ}$ and 90 and $270^{\circ}$ were averaged for equal off-nadir angles).

The cover types reported in this study included a plowed field, annual grassland, steppe grassland, hard wheat, salt plain, and irrigated wheat. A detailed description of these cover types are as follows. A photograph of each cover type is presented in Fig. 2 and a summary of the times of measurement and the surface agronomic characteristics are shown in Table 1. The size of the larger clods of the plowed soil were on the order of $8 \mathrm{~cm}$ diameter. The annual grassland had $<5 \%$ vegetation cover consisting of Cynodon dactylon, Plantago ssp., Angallis arvensis, Cutandia dichotoma, Medicago arabica, Reseda alba, and composites. Pebbles and stones covered $40 \%$ of the surface. The steppe grass (Stipa Tenacissima) occurred on a shallow, stony soil over a hard calcrete crust. The steppe grass covered a total of $18 \%$ of the ground. The characteristic clumps of steppe grass 


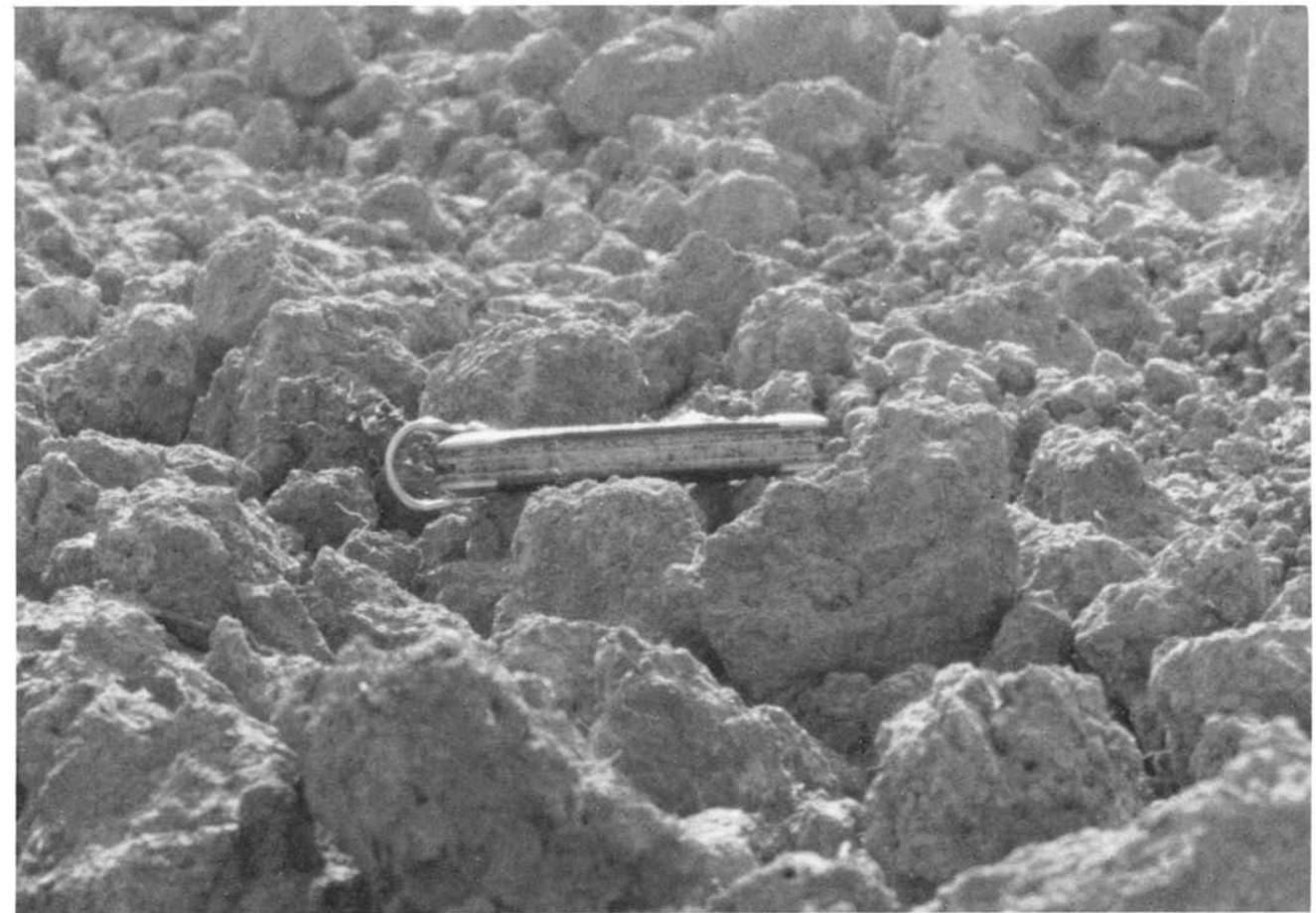

(a)

(b)

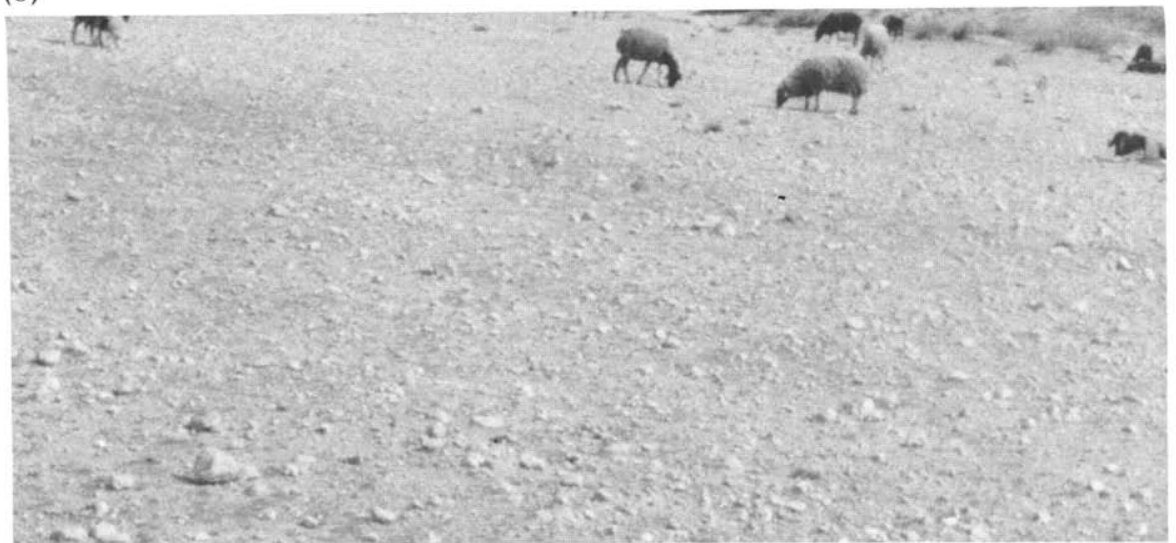

FIGURE 2. Cover types measured in this study. The object in the plowed field is $9.5 \mathrm{~cm}$ long. (a) Plowed field. (b) Annual grassland. (c) Steppe grassland. (d) Hard wheat. (e) Salt plain. (f) Irrigated wheat.

(Fig. 2) covered $25 \%$ of the surface and each clump covered $70 \%$ of the ground beneath. The clumps of vegetation had on the order of $20 \%$ green vegetation. Sheet erosion caused each clump of vegetation to appear as a mound. The mean height of the maximum vegetation height of each clump was $38 \mathrm{~cm}$. The unirrigated hard wheat (Triticum Durum) had a mean vegetation height of $46 \mathrm{~cm}$ and a 14\% 


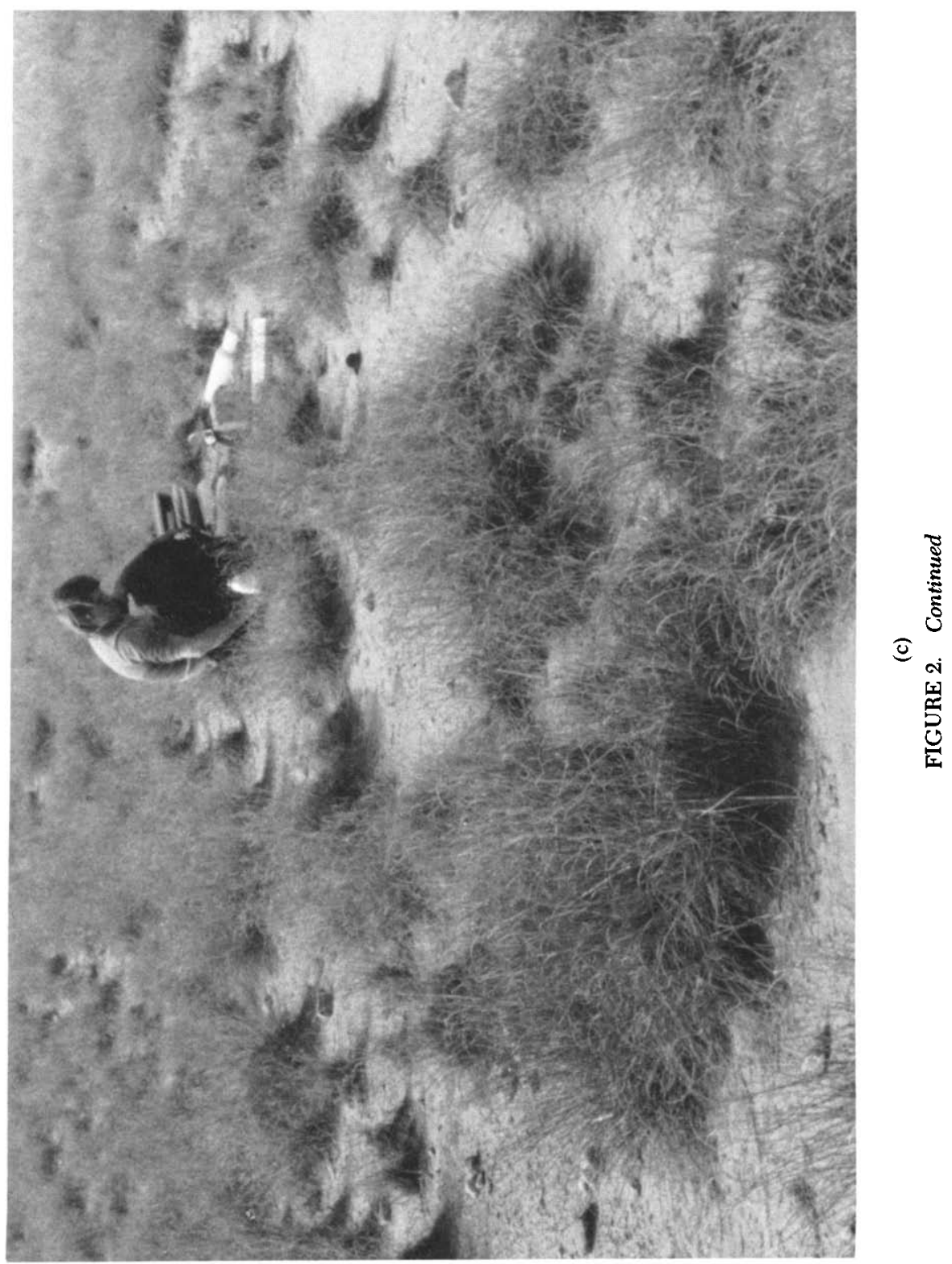




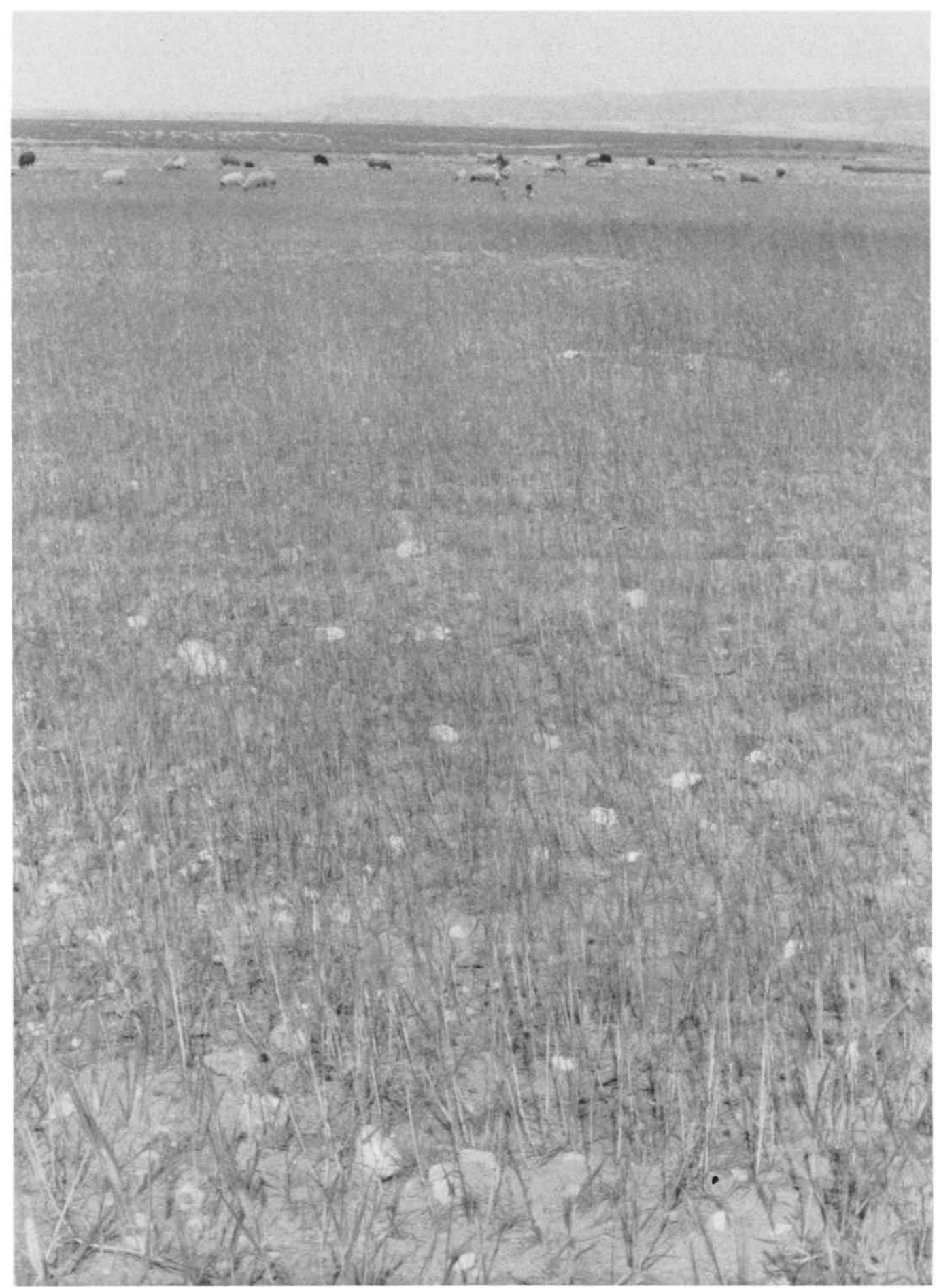

(d)

FIGURE 2. Continued 


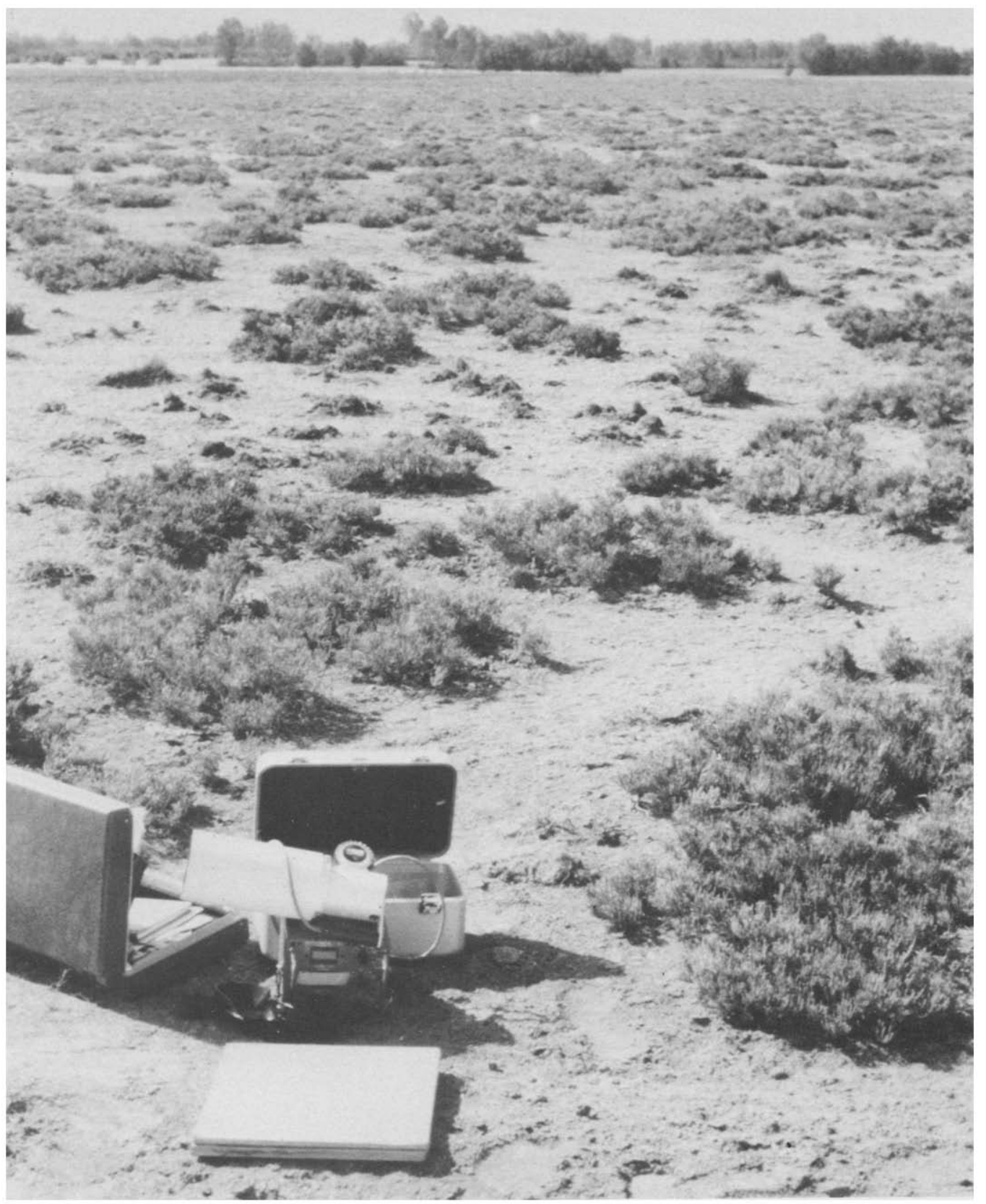

(e)

FIGURE 2. Continued 


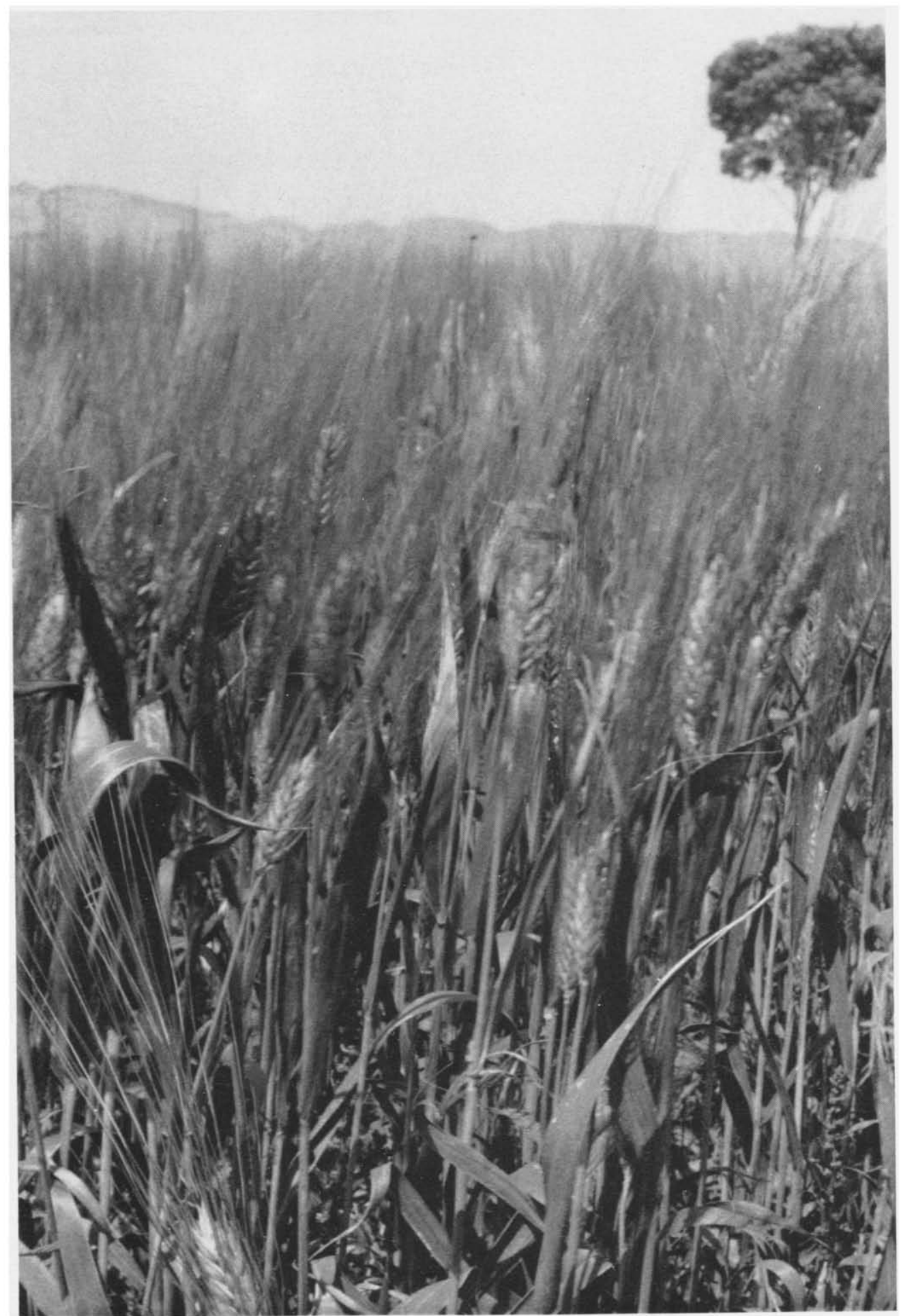

(f)

FIGURE 2. Continued 
TABLE 1 Date, Standard Time, Solar Zenith Angle, and Vegetation Characteristics during Each Radiometric Measurement of a Cover Type

\begin{tabular}{|c|c|c|c|c|c|}
\hline \multirow[b]{2}{*}{ COVER TyPE } & \multirow[b]{2}{*}{ Date } & \multirow[b]{2}{*}{$\begin{array}{c}\text { STandard } \\
\text { TIME }\end{array}$} & \multirow{2}{*}{$\begin{array}{c}\text { Solar } \\
\text { ZENITH } \\
\text { ANGLE } \\
\left({ }^{\circ}\right)\end{array}$} & \multicolumn{2}{|c|}{ VEGETATION } \\
\hline & & & & $\begin{array}{c}\text { HEIGHT } \\
\text { (CM) }\end{array}$ & $\begin{array}{c}\text { \% Total } \\
\text { Cover }\end{array}$ \\
\hline \multirow{4}{*}{ Plowed field } & $4 / 28 / 83$ & $7: 33$ & 64 & - & - \\
\hline & & 9:09 & 45 & & \\
\hline & & $10: 45$ & 30 & & \\
\hline & & $12: 17$ & 26 & & \\
\hline \multirow[t]{3}{*}{ Annual grassland } & $4 / 27 / 83$ & $8: 43$ & 50 & $<3$ & $<5$ \\
\hline & & $10: 53$ & 30 & & \\
\hline & & $12: 54$ & 28 & & \\
\hline \multirow[t]{3}{*}{ Steppe grass } & $4 / 27 / 83$ & $7: 55$ & 63 & 38 & 18 \\
\hline & & $10: 17$ & 35 & & \\
\hline & & $12: 22$ & 27 & & \\
\hline \multirow[t]{3}{*}{ Hard wheat } & $4 / 27 / 83$ & $8: 21$ & 51 & 46 & 14 \\
\hline & & $10: 35$ & 32 & & \\
\hline & & $12: 36$ & 27 & & \\
\hline \multirow[t]{3}{*}{ Salt plain } & $5 / 6 / 8$ & $8: 46$ & 48 & 9 & 20 \\
\hline & & $9: 55$ & 36 & & \\
\hline & & 12:05 & 23 & & \\
\hline \multirow{4}{*}{ Irrigated wheat } & $4 / 28 / 83$ & $7: 54$ & 59 & 76 & 70 \\
\hline & & $9: 32$ & 42 & & \\
\hline & & 11:08 & 28 & & \\
\hline & & $12: 25$ & 26 & & \\
\hline
\end{tabular}

ground cover. Ninety-five percent of the vegetation material was green. The salt plain consisted of a clayey soil covered mainly with Suaeda spp. The vegetation cover was $20 \%$ with the characteristic clumped vegetation (Fig. 2). The mean of the maximum canopy heights of each clump was only on the order of $9 \mathrm{~cm}$. The irrigated wheat (Triticum Aestivum) was $76 \mathrm{~cm}$ in height and was to be harvested around 14 May 1983. The percent cover was $70 \%$.

Finally, the normalized difference (ND) transformation, (Band $2-$ Band 1) $/($ Band $2+$ Band 1), was calculated for each data set. This transformation has been useful in monitoring vegetation cover of large continental regions (Tucker et al., 1983a,b). The ND data were plotted in the polar plot distributions in the same manner as the reflectance data. These distributions were analyzed in regard to their topology and variations in signal with view direction.

\section{Results and Discussions}

Figures 3 and 4 show the directional reflectance distributions of the plowed field in AVHRR Bands 1 and 2, respectively. These distributions all show a strong backscatter peak in the direction toward the sun. The reflectance decreases in all directions away from this backscatter peak. The minimum reflectance occurs in extreme off-nadir view angle in the $0^{\circ}$ azimuth (forward scatter direction). These distributions of bare soil are very 

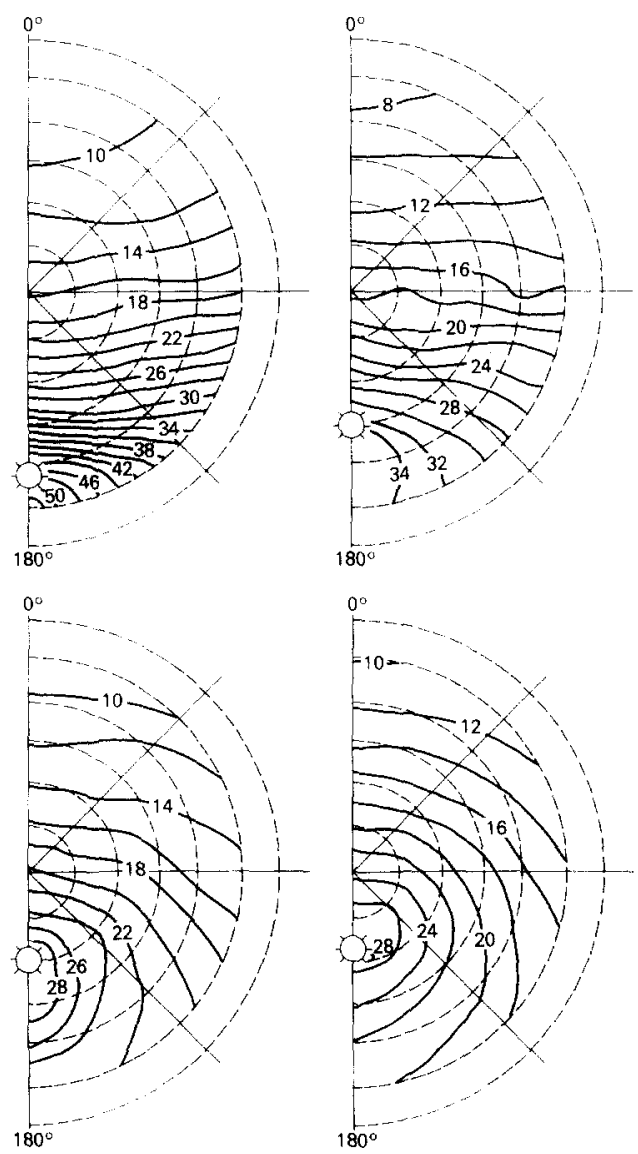

FIC;URE :3. Directional reflectance factor distributions of a plowed field for AVHRR Band $1(0.58-0.68 \mu \mathrm{m})$. The solar position for each distribution is indicated by the star. Equal lines of percent reflectance are contoured. The polar coordinate system used for plotting is described in detail in Fig. 1.

similar to those reported by Kimes (1983). He presented a physical explanation for these observed trends. A summary of this explanation is that soils have relatively opaque vertical structures (whether they be fine gains or large clods as seen in Fig. 2) that cause dark shadows. The peak reflectance occurs in the antisolar direction (backscatter toward the sun) because in this direction only those surfaces which are in direct sunlight are viewed by the sensor. As the sensor direction moves away from the antisolar direction, the fol-
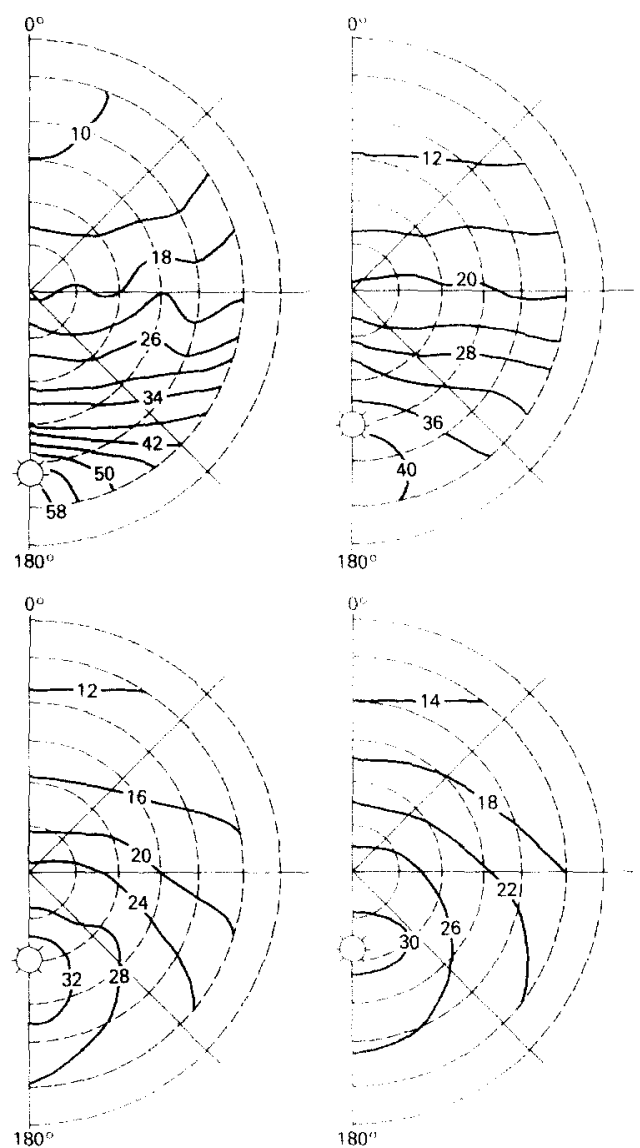

FIC:URE 4. Directional reflectance factor distributions of a plowed field for AVHRR Band $2(0.73-1.1 \mu \mathrm{m})$. Symbols, lines, and numbers as in Fig. 3.

lowing two mechanisms cause the reflectance to decrease: (1) in the sensor's field of view the relative proportion of shadowed surfaces increases and (2) the proportion of particle facets with normals that deviate from the solar direction increases causing decreased solar irradiance on these facets (cosine function).

Figures 5 and 6 show the directional reflectance distributions of the annual grassland in AVHRR Bands 1 and 2, respectively. The annual grassland was a pebble strewn surface with less than $5 \%$ vegetation cover. The pebbles are opaque, vertical structure as are soil particles, and 

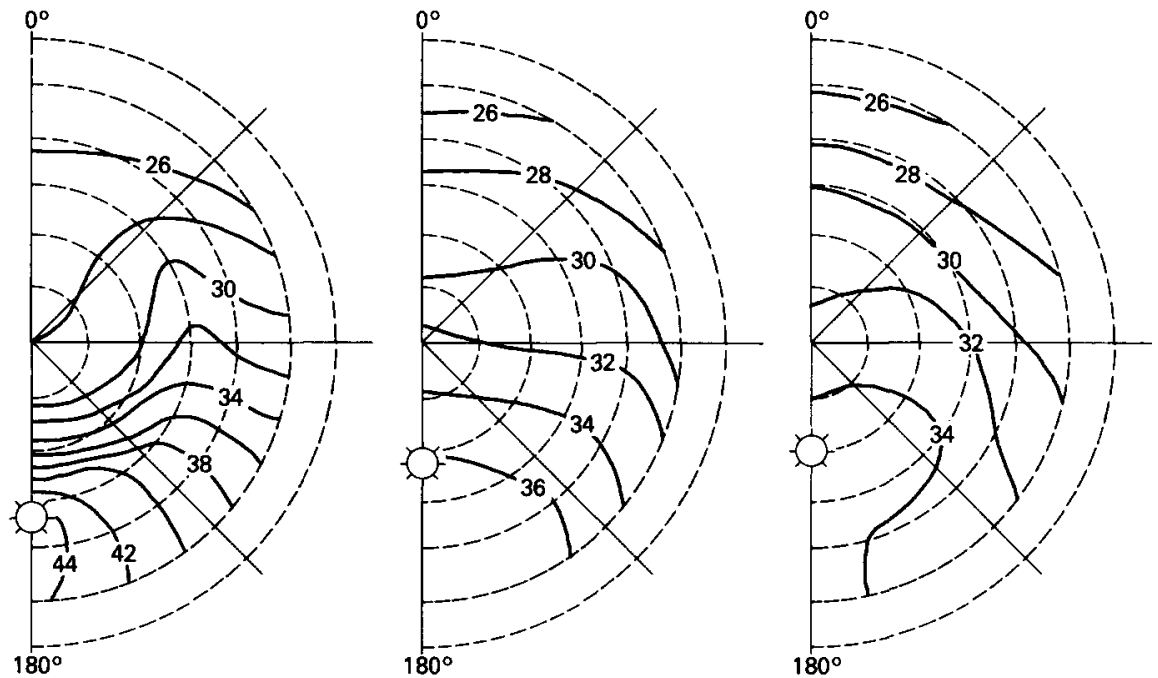

FIGURE 5. Directional reflectance factor distributions of an annual grassland for AVHRR Band 1 $(0.58-0.68 \mu \mathrm{m})$. Symbols, lines, and numbers as in Fig. 3.

thus the topology of the reflectance distributions in Figs. 5 and 6 look very similar to those of bare soil. However, the general magnitude of the reflectance values for the annual grasslands is higher than for the soil surface due to the highly reflective calcarious pebbles.

The directional reflectance distributions of the steppe grassland are shown in
Figs. 7 and 8 . In both Bands 1 and 2 the reflectance distributions are very typical of bare soil. The percent cover was $18 \%$, and consequently the scattering properties of the soil are dominating. The effect of the clumps of vegetation is to increase the probability of gap to the soil for any particular view angle relative to evenly or randomly space vegetation.
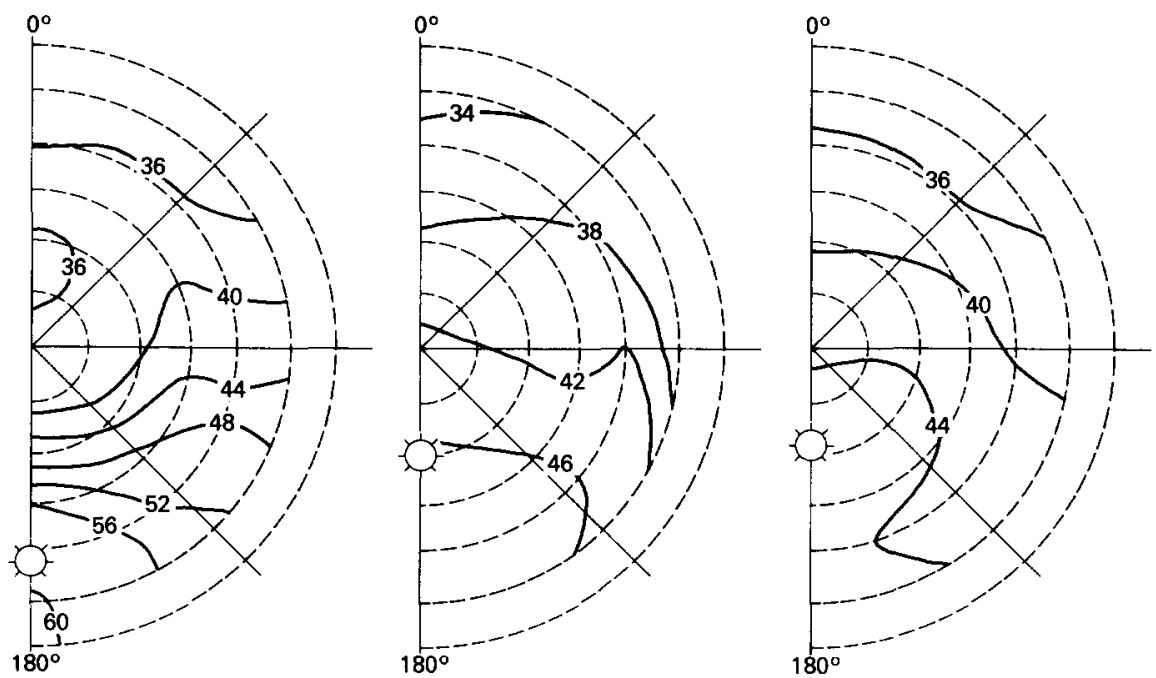

FIGURE 6. Directional reflectance factor distributions of an annual grassland for AVHRR Band 2 $(0.73-1.1 \mu \mathrm{m})$. Symbols, lines, and numbers as in Fig. 3. 

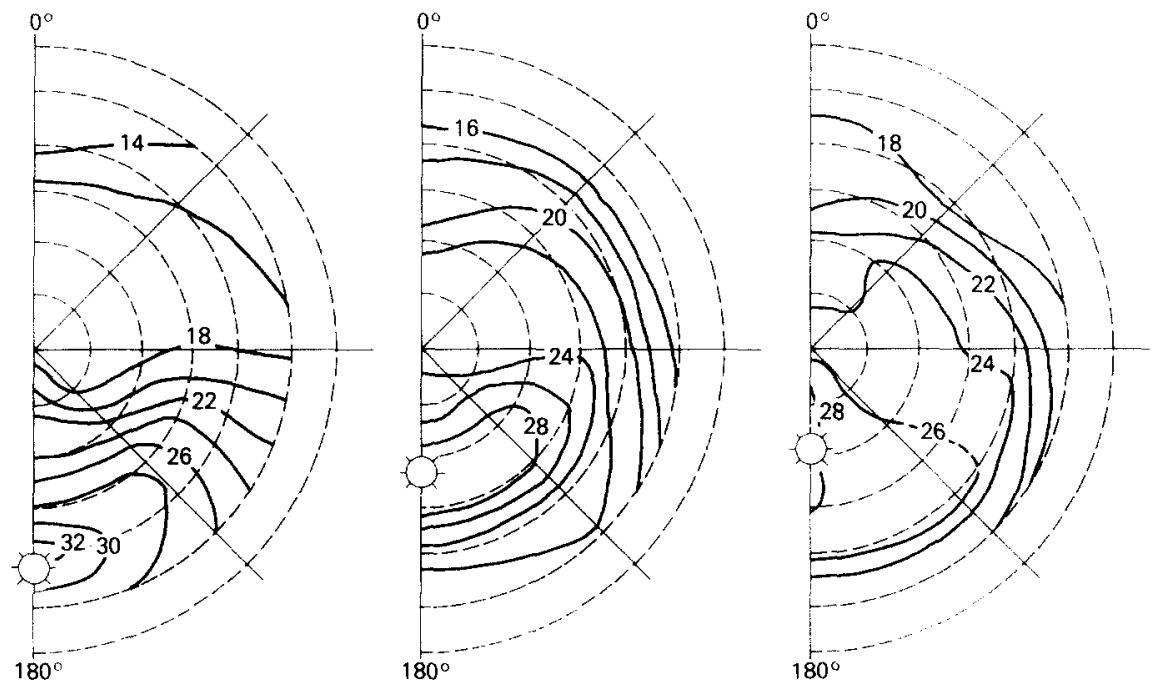

FIGURE 7 . Directional reflectance factor distributions of a steppe grassland for AVHRR Band 1 $(0.58-0.68 \mu \mathrm{m})$. Symbols, lines, and numbers as in Fig. 3.

The directional reflectance distribu- through canopy as a function of off-nadir tions in Band 1 of hard wheat are shown in Fig. 9. The distribution looks very similar in topology to the soil distributions. The explanation is as follows. The percent vegetation cover was only $14 \%$. Using this information and assuming an erectophile distribution (deWit, 1965), the leaf area index and the probability of gap $[P(\theta)]$ angle was calculated using the equations presented and discussed by Kimes (1984). The LAI was 0.44 and the $P(\theta)$ values for $0,25,50$, and $75^{\circ}$ were $0.86,0.83,0.71$, and 0.39 , respectively. In Band 1 the soil and leaf reflectance are on the order of 0.25 and 0.05 , respectively. In Fig. 9(a), the solar zenith angle is $51^{\circ}$. Using the
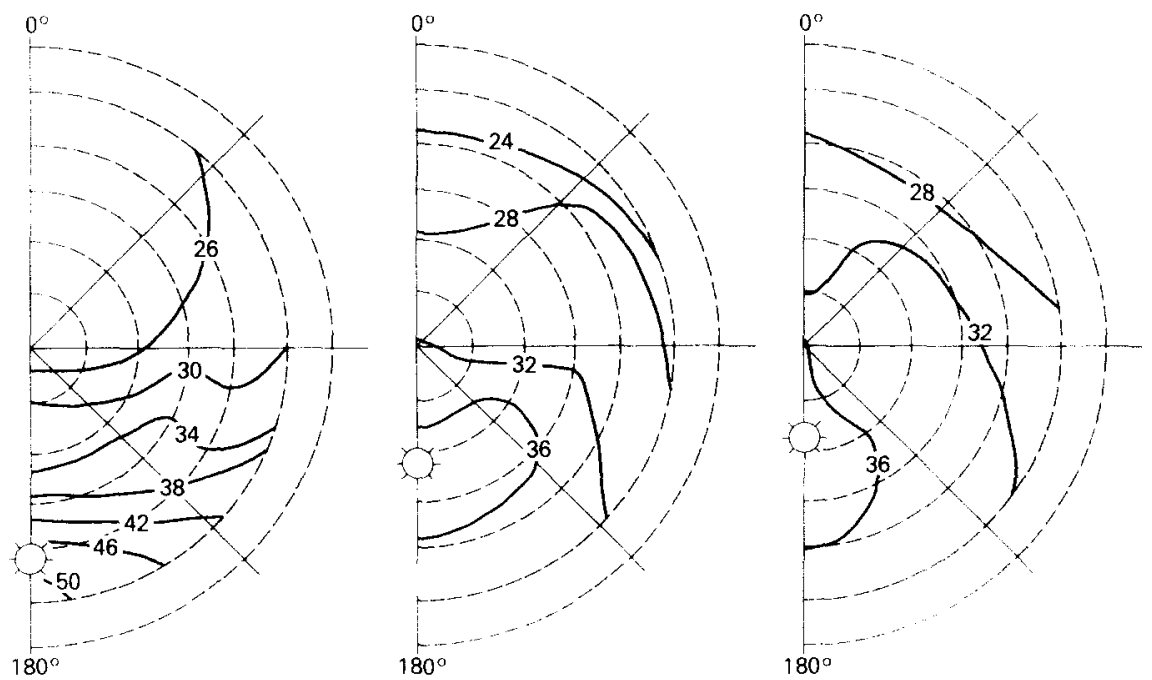

FIGURE \&. Directional reflectance factor distributions of a steppe grassland for AVHRR Band 2 $(0.73-1.1 \mu \mathrm{m})$. Symbols, lines, and numbers as in Fig. 3. 

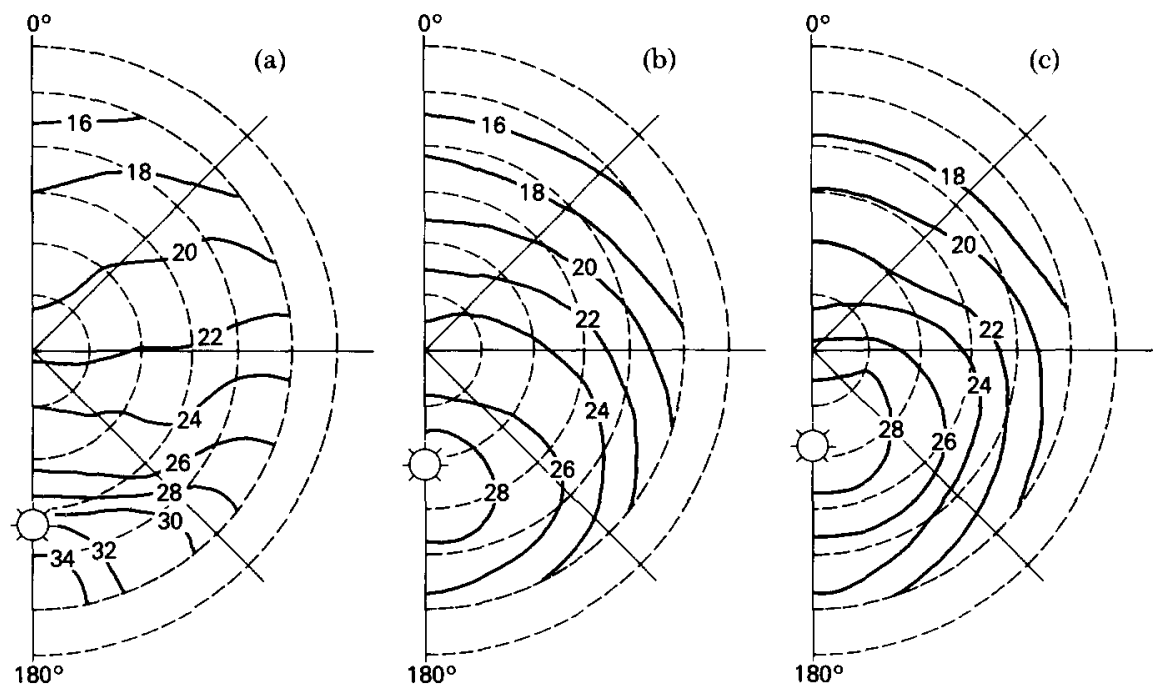

FIGURE 9. Directional reflectance factor distributions of a hard wheat for AVHRR Band 1 $(0.58-0.68 \mu \mathrm{m})$. Symbols, lines, and numbers as in Fig. 3.

above information $71 \%$ of the direct solar flux hits the soil $\left[P\left(51^{\circ}\right) \simeq 71 \%\right]$ while $24 \%$ hits the vegetation. Because $71 \%$ of the direct solar flux hits the soil and the soil reflectance is 5 times the leaf reflectance value, the soil scattering properties clearly dominate the reflectance distribution. As the solar zenith angle decreases [Figs. 9(b),(c)] the $P(\theta)$ increases, and thus the soil scattering properties dominate the reflectance distribution even more. As the solar zenith angle increases, eventually the percent of direct flux reaching the soil would become relatively small and the scattering properties of the vegetation would dominate the reflectance distribution of the scene. This has been demonstrated by Kimes (1983).

Figure 10 shows the reflectance distributions of hard wheat in Band 2. In contrast to Band 1, Band 2 distributions show a clear influence of the scattering properties of both the vegetation and soil. In Band 2 the soil and leaf reflectance are on the order of 0.25 and 0.46 , respectively. In Band 2 the leaf reflectance is 1.8 times the soil reflectance. In Band 1 the same factor was only 0.20 . Thus, for the same $P(\theta)$ values the scattering properties of the vegetation should influence the reflectance distribution much more in Band 2 than in Band 1. As a consequence, the strong backscatter peak of the soil is greatly dominated at all sun angles. As discussed above the strongest influence of soil scattering occurs at small solar zenith angles. For example, Fig. 10(c) shows a backscatter peak in the direction of the sun and a minimum at the extreme offnadir direction in the forward scatter direction $\left(0^{\circ}\right.$ azimuth). This trend is typical for a bare soil; however, the overall variation is small as compared to bare soil due to the effect of the vegetation scattering.

As the solar zenith angle increases the $P(\theta)$ to the soil decreases and the vegetation scattering dominates more [Fig. 10(a)]. In general, the vegetation scattering (disregarding effect of the soil) causes the reflectance to increase with increasing off-nadir view angle for all azimuth view directions and sun angles. This general 

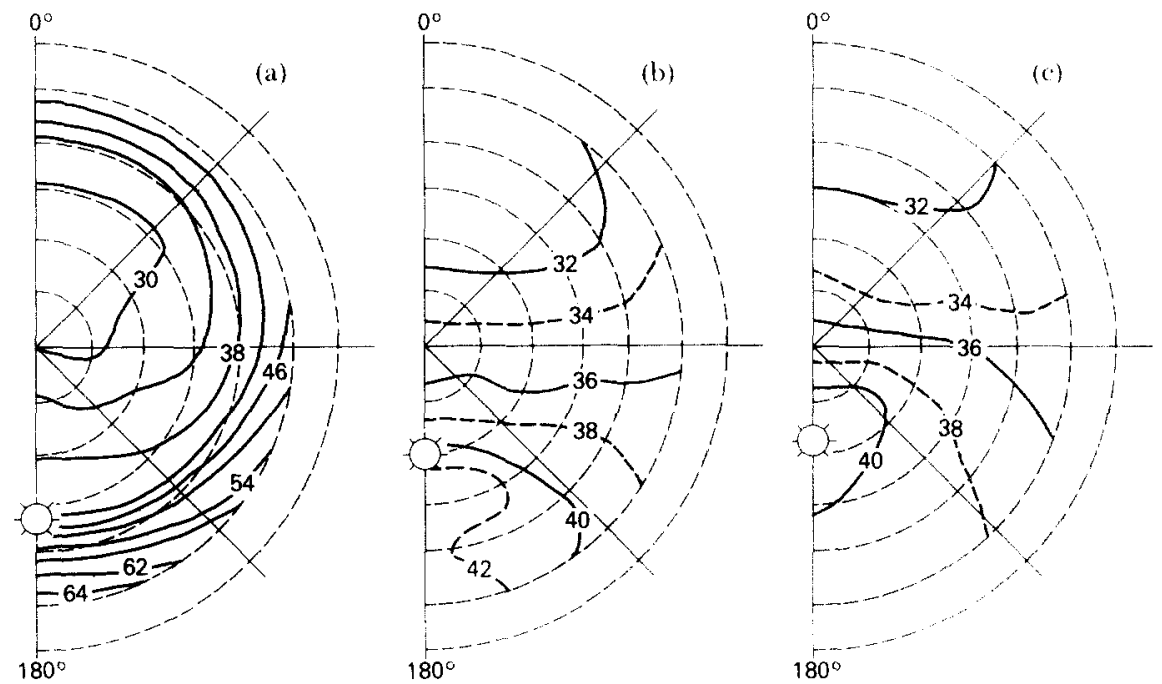

FIGURE 10. Directional reflectance factor distributions of an hard wheat for AVHRR Band 2 $(0.75-1.1 \mu \mathrm{m})$. Symbols, lines, and numbers as in Fig, 3.

trend is documented with field measurements of complete vegetation canopies (Kirchner et al., 1982; Kimes, 1983) and explained by physically based vegetation models (Kimes, 1984). Briefly, the trend is caused by the shading of lower canopy layers by the components in the upper layers and by viewing different proportions of layer components as the sensor view angle changes. The phenomenon is discussed further below and is documented in detail by Kimes (1983; 1984) and is referred to here as Effect 1 . Thus in Fig. 10(a) the scattering of the vegetation is dominant. However, the soil still has some effect and may in part be responsible for causing the shift of the minimum reflectance off-nadir in the forward scattering direction ( $0^{\circ}$ azimuth). A pure soil distribution has its minimum at the extreme off-nadir view angle in the forward scatter direction. Another phenomenon which may be causing this shift of reflectance is subtle scattering properties of a canopy due strictly to the geometric orientations of the leaves. This phenomenon is not readily intuitive and is discussed in detail by Kimes (1984).

The underlying principles of Effect 1 are as follows. If we consider any abstract homogeneous canopy with multiple layers of equal leaf geometry, density, and optical properties, the probability of gap to any particular canopy depth generally decreases as the off-nadir angle of view increases. Furthermore, for any particular view direction the probability of gap decreases with increasing depth into the canopy. These phenomena are a direct result of the canopy's geometric structure. For all irradiance conditions, this structure causes the scattered solar flux from the components to be maximum at the top of the canopy and decrease to a minimum at the bottom of the canopy. It is also clear that this structure causes the proportion of components viewed at any given depth (or layer) to decrease with increasing off-nadir view angle. Thus, the ultimate result is that the reflectance increases with increasing off-nadir view angle because, in the sensor's field of view, 

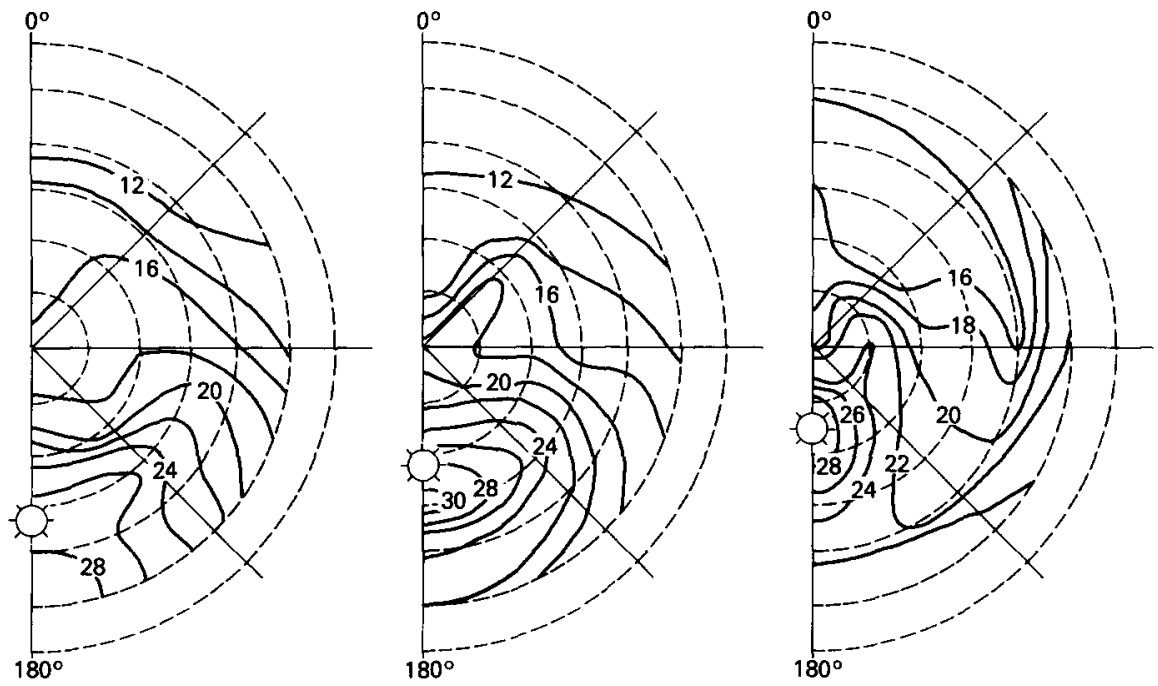

FIGURE 11. Directional reflectance factor distributions of a salt plain for AVHRR Band 1 $(0.58-0.68 \mu \mathrm{m})$. Symbols, lines, and numbers as in Fig. 3.

the proportion of upper canopy components that scatter the largest amount of solar flux increases and the proportion of lower canopy components that scatter the lowest amount of solar flux decreases. It follows that the minimum reflectance should occur near nadir. Furthermore, the increase of reflectance with increasing off-nadir view angle should be the great- est when the sun is near the horizon and should be minimal when the sun is near the zenith. All of these trends are clearly demonstrated by simulated field data (Kimes 1983; 1984).

Figures 11 and 12 show the reflectance distributions of the salt plain for Band 1 and 2 , respectively. The distributions are similar to bare soil. The percent vegeta-
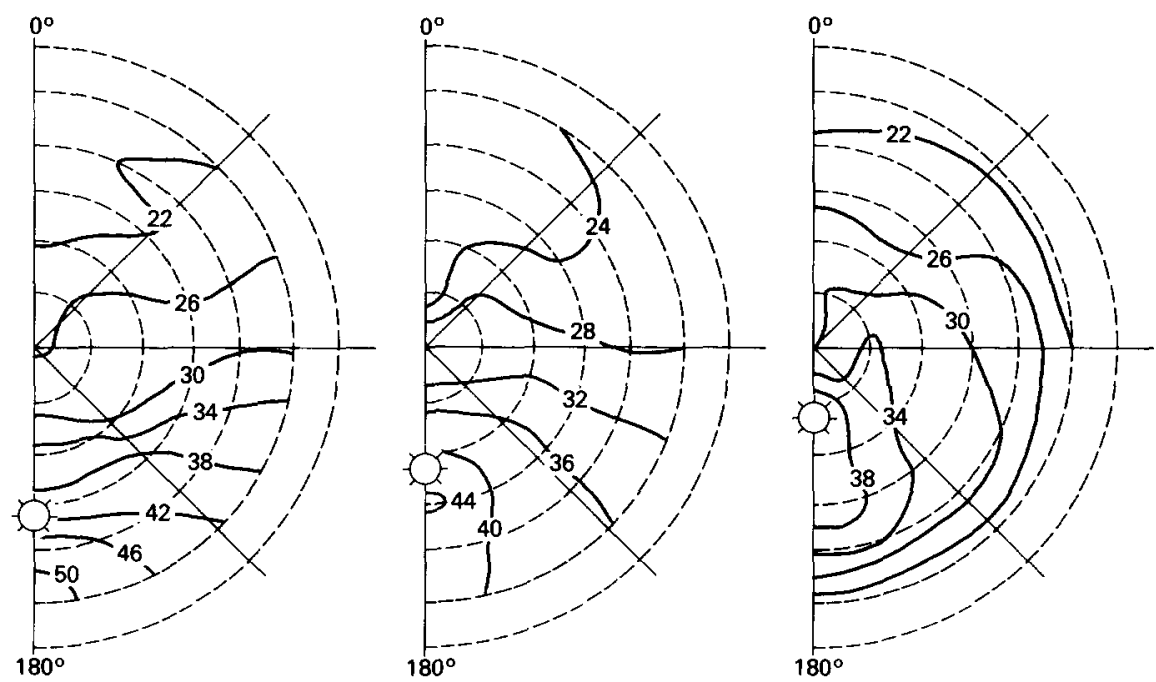

FIGURE 12. Directional reflectance factor distributions of a salt plain for AVHRR Band 2 $(0.73-1.1 \mu \mathrm{m})$. Symbols, lines, and numbers as in Fig. 3. 
tion cover was approximately $20 \%$. Furthermore, the vegetation characteristically forms clumps causing a relatively high probability of gap to the soil for any particular view angle relative to evenly or randomly spaced vegetation. Furthermore, the height of the vegetation in the clumps was only $9 \mathrm{~cm}$ and thus the projection of these clumps (or probability of gap between the clumps) would change minimally with changing view angle as compared to taller forms of vegetation. And, finally the vegetation reflectance was actually lower than the soil reflectance in
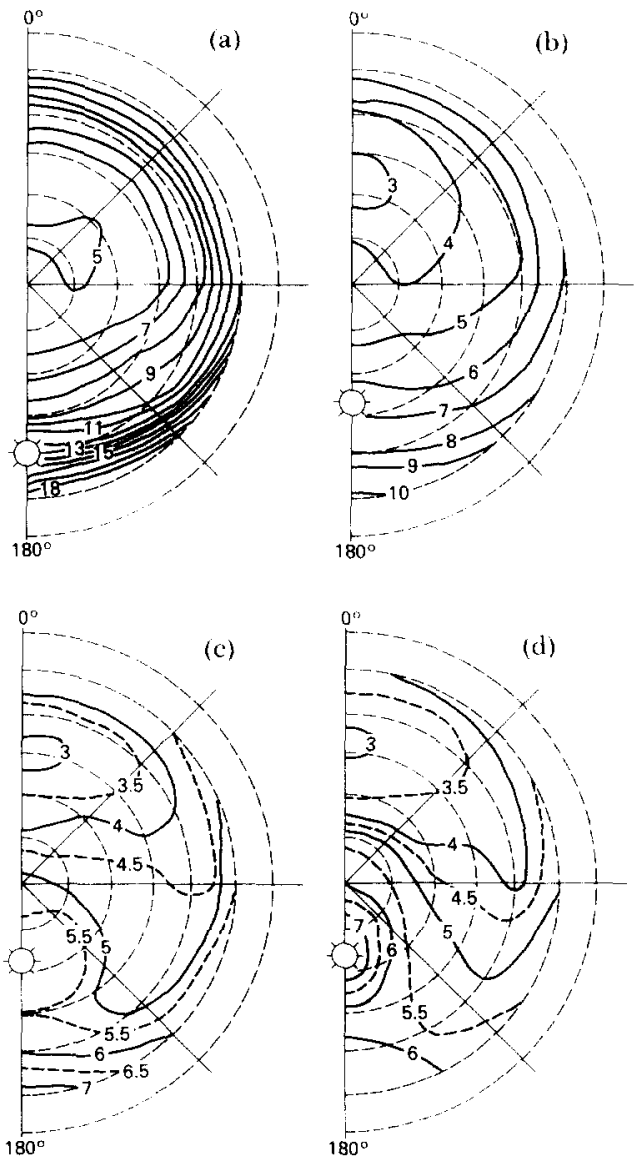

FIC;URE 13. Directional reflectance factor distributions of an irrigated wheat field for AVHRR Band 1 (0.58-0.68 $\mu \mathrm{m})$. Symbols, lines, and numbers as in Fig. 3 .
Band 2 (vegetation $\rho=0.25$, soil $\rho=$ 0.30 ) ; generally the opposite situation is true. All of these facts cause the effects of the scattering properties of the vegetation on the reflectance distribution to be smaller than usual.

Figures 13 and 14 show the reflectance distributions of the irrigated wheat. The percent ground cover was 70\%. Assuming an erectophile canopy the LAI was 4.0, and the probabilities of gap to the soil for off-nadir angles of 25,50 , and $75^{\circ}$ were $0.19,0.04$, and 0.00 , respectively. For low sun angles [e.g., Fig. 13(a)] the scattering
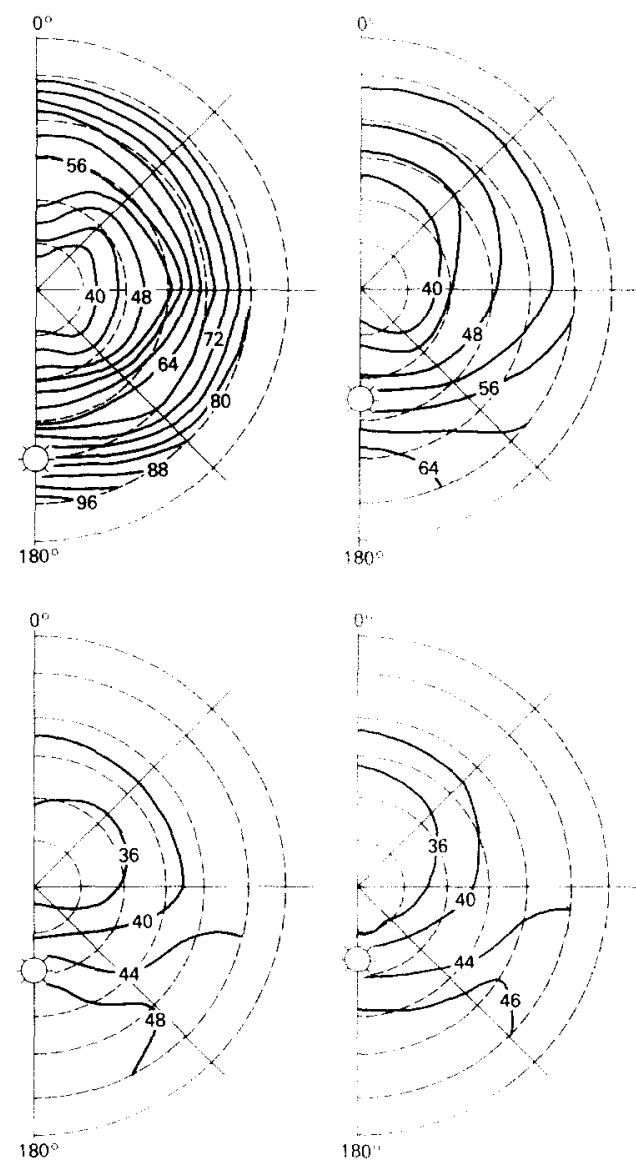

FIGURE 14. Directional reflectance factor distributions of an irrigated wheat field for AVHRR Band $2(0.73-1.1$ $\mu \mathrm{m})$. Symbols, lines, and numbers as in Fig. 3. 
properties of the vegetation dominates for the same reasons discussed above (Effect 1). As the solar zenith angle decreases [Fig. 13(d)] more soil is directly illuminated, and we begin to see the influences of the soil scatter properties in the reflectance distribution-peak backscatter toward the sun, and minimum reflectance point shifted to far off-nadir angles in the forward scatter direction. In contrast to Band 1, Band 2 does not show as much influence of soil scattering at small solar zenith angles because the leaf reflectance is on the order of 1.8 times the soil reflectance in Band 2.

Figure 15 shows plots of the normalized difference for selected cover types and solar zenith angles. Tucker et al. $(1983 a, b)$ have shown the utility of this transformation of AVHRR data in monitoring the vegetation cover of large continental regions. One of the problems with utilizing AVHRR data directly is that the radiometer scans cross track $\pm 56^{\circ}$ from nadir. Such large variations in view angle can cause significant variations in signal from the same target. These variations must be minimized or corrected for in real time applications. Holben and Fraser (1983), Holben et al. (1984), and Kimes et al. (1984) have demonstrated that the ND transformation minimizes the view angle effects for a number of surface types. Figure 15 also demonstrates this effect on the surfaces in this study for all solar zenith angles. Comparing these ND distributions to the corresponding reflectance distributions for Bands 1 and 2, it is evident that the ND transformation generally decreases the variation of signal with changing view angle. For example, the percent maximum variation [calculated as the ((maximum value - minimal value)/maximum value) $\times 100$ ] of the ND distributions for irrigated wheat, hard wheat, and plowed field (Fig. 15) are $16 \%, 54 \%$, and $29 \%$, respectively. The corresponding maximum variations for Band 1 are $75 \%, 52 \%$, and $79 \%$, respectively, and for Band $249 \%, 52 \%$, and
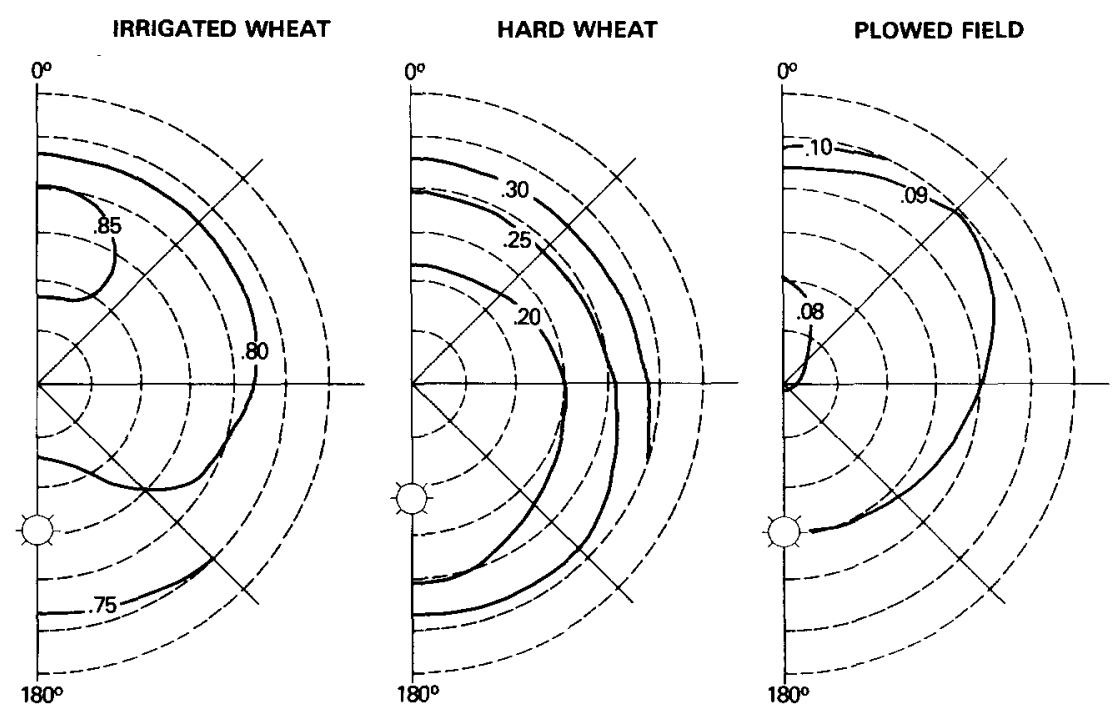

FIGURE 15. Directional normalized difference distribution for three selected cover types. The normalized difference for each view angle was calculated as (Band $2-$ Band 1$) /($ Band $1+$ Band 2). Symbols, lines, and numbers as in Fig. 3. 
TABLE 2 Percent Maximum Variations Out to $45^{\circ}$ Nadir for All Measured *

\begin{tabular}{|c|c|c|c|c|}
\hline $\begin{array}{l}\text { Cover } \\
\text { TYPE }\end{array}$ & $\begin{array}{c}\text { Solar } \\
\text { ZeNith } \\
\text { ANGLE } \\
(0)\end{array}$ & $\begin{array}{c}\text { NoRMalized } \\
\text { DifFERENCE }\end{array}$ & BAND 1 & BAND 2 \\
\hline \multirow[t]{4}{*}{ Plowed field } & 64 & 74 & 70 & 74 \\
\hline & 45 & 13 & 69 & 74 \\
\hline & 30 & 24 & 60 & 58 \\
\hline & 26 & 23 & 53 & 51 \\
\hline \multirow[t]{3}{*}{ Annual grassland } & 50 & 20 & 40 & 39 \\
\hline & 30 & 7 & 24 & $2 ; 3$ \\
\hline & 28 & 10 & 18 & 17 \\
\hline \multirow[t]{3}{*}{ Stipa } & 63 & $1: 3$ & 40 & 38 \\
\hline & 35 & 25 & 40 & 35 \\
\hline & 26 & 22 & 32 & 29 \\
\hline \multirow[t]{3}{*}{ Hard wheat } & .51 & 30 & 38 & 40 \\
\hline & 32 & 30 & 3.5 & 28 \\
\hline & 27 & 29 & 32 & 24 \\
\hline \multirow[t]{3}{*}{ Salt plain } & 48 & 44 & 48 & 46 \\
\hline & 36 & 45 & $6: 3$ & 53 \\
\hline & 23 & 42 & 53 & 46 \\
\hline \multirow[t]{4}{*}{ Irrigated wheat } & 59 & 12 & 45 & 43 \\
\hline & 42 & 10 & $6: 3$ & 42 \\
\hline & 28 & 14 & 53 & 36 \\
\hline & 26 & 16 & 60 & 31 \\
\hline
\end{tabular}

"Distributions: the maximum variation was calculated as [(maximum value minimal value) $/$ maximum value $] \times 100$.

$78 \%$, respectively. In general Holben et al. (1984) and Kimes et al. (1984) found that the ND transformation applied to off-nadir view angles of less than $45^{\circ}$ greatly reduced variations in signal with changing off-nadir view angles. Ignoring off-nadir view angles past $45^{\circ}$ the maximum variation for the ND distributions were $10 \%, 30 \%$, and $13 \%$, respectively. The corresponding maximum variations for Band 1 are $63 \%, 35 \%$, and $69 \%$, respectively, and for Band 2 are $42 \%, 28 \%$, and $74 \%$, respectively. Table 2 shows the maximum variations out to $45^{\circ}$ off-nadir for all cover types and sun angles. In general, the ND significantly reduces variation as compared to single bands; however, there are exceptions (Table 2).

\section{Conclusions}

The directional reflectance distribution of the entire exitance hemisphere as a function of sun angle were presented for six surfaces characteristic of northern Africa. The annual grassland, steppe grassland, and salt plain had geometric structures that were extreme as compared to the vegetation types reported in the literature. Strong anisotropic trends were documented. The largest variations in reflectance occurred at large solar zenith angles for bare soils and grasslands with very low vegetation covers. As vegetation densities increased and the solar zenith angle decreased, reflectance variations decreased. The topology of the distribu- 
tions studied seem to be very similar to the distributions of natural vegetation canopies measured by Kimes (1983) and Kirchner et al. (1982). Furthermore, the data supported the physical principles responsible for the observed dynamics as proposed by Kimes (1983; 1984). Past studies have demonstrated that the normalized difference (ND) transformation is useful in monitoring vegetation cover. It was demonstrated in this study that the (ND) transformation generally decreased the directional variation of the signal. However, there were exceptions. For each remote sensing application the user should be aware of these variations for the specific cover types being studied, solar zenith angle and scanning direction of the sensor with respect to the solar azimuth.

The fieldwork and measurements of this study were made possible by close cooperation between NASA/GSFC and the ITC.

\section{References}

deWit, C. T. (1965), Photosynthesis of leaf canopies, Institute for Biological and Chemical Research on Field Crops and Herbage, Centre for Agricultural Publications and Documentation, Rept. 663, Wageningen, The Netherlands, $57 \mathrm{pp}$.

Holben, B. N., and Fraser, S. (1983), Red and near-infrared sensor response to off-nadir viewing, Int. J. Remote Sens. 5:145-160.

Holben, B. N., Kimes, D. S., and Fraser, S. (1984), Directional reflectance response in AVHRR red and near-IR bands for three cover types and varying atmospheric conditions, Remote Sens. Environ., forthcoming.

Kimes, D. S. (1983), Dynamics of directional reflectance factor distributions for vege- tation canopies, Appl. Opt., 22:1364-1372.

Kimes, D. S. (1984), Modeling the directional reflectance from complete homogeneous vegetation canopies with various leaf orientation distributions, Opt. Soc. Am., forthcoming.

Kimes, D. S., and Kirchner, J. A. (1982a), Irradiance measurement errors due to the assumption of a Lambertian reference panel, Remote Sens. Environ. 12:141-149.

Kimes, D. S., and Kirchner, J. A. (1982b), Radiative transfer model for heterogeneous 3-D scenes, Appl. Opt. 21:4119-4129.

Kimes, D. S., Holben, B. N., Tucker, C. J., and Newcomb, W. W. (1984), Optimal directional view angles for remote sensing missions, Int. J. Remote Sens., forthcoming.

Kirchner, J. A., Kimes, D. S., and McMurtrey, J. E., III (1982), Variation of directional reflectance factors with structural changes of a developing alfalfa canopy, Appl. Opt. 21:3766-3774.

Smith, J. A., and Ranson, K. J. (1979), MRS Literature Survey of Bidirectional Reflectance, ORI, Inc., Contract Report to NASA/Goddard Space Flight Center, Greenbelt, MD, Oct.

Tucker, C. J., Jones, W. H., Kley, W. A., and Sundstrom, G. J. (1981), A three band hand held radiometer for field use, Science 211:281-283.

Tucker, C. J., Townshend, J. R. G., and Goff, T. E. (1983a), African land cover classification using satellite data, Science 227:369-375.

Tucker, C. J., Vanpraet, C., Boerwinkel, C., and Gaston, A. (1983b), Satellite remote sensing of total dry matter production in the Senegalese Sahel, Remote Sens. Environ. 13:461-474.

Received 25 July 1984; revised 2 November 1984. 